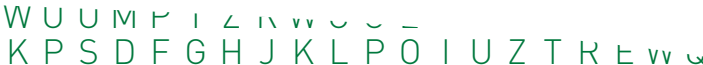

S Y K VHGFDSAYVNPIZRWQSCGZNJ

KO I A GRDCKIOPMNESWLNCXWZYKFEL,

O GN L Z D S Q O M D N V US GR V L GR VKGECEM J b.

NRL V J GD I NGREXOMNYAZTEWNFX J LRMDSA U,

C E B E L T I A N D S C H A I NWD R I V E S N V R D J Y KF E Q L O,

Y A H I N CWQY J A OBRELNFXTJOLKQFHBKGECLZEMS,

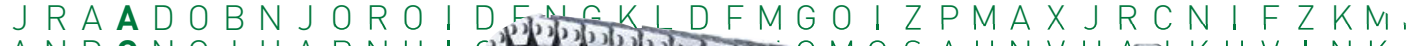

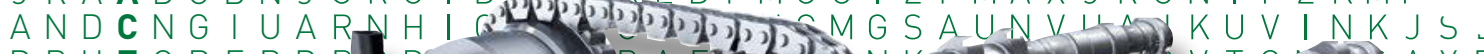

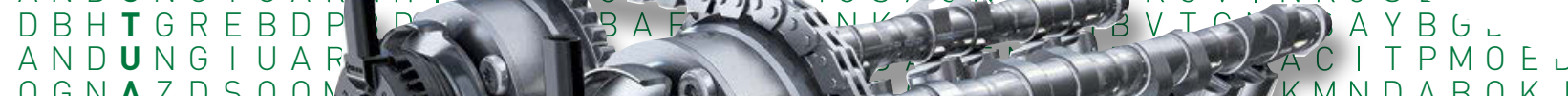

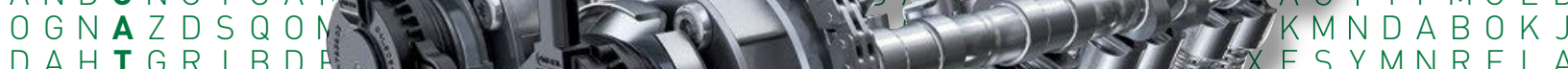

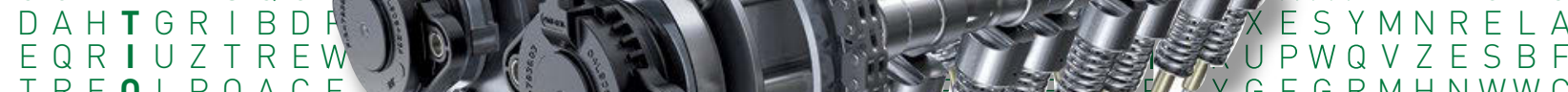
TREOLPQACE

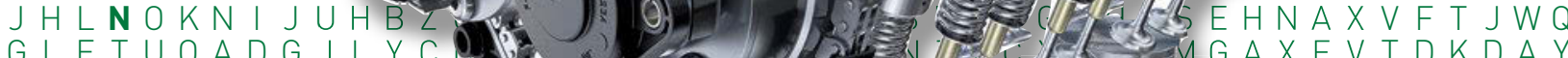

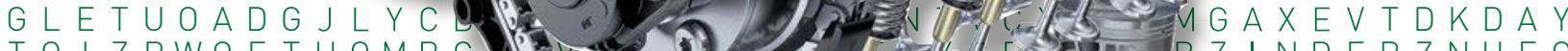

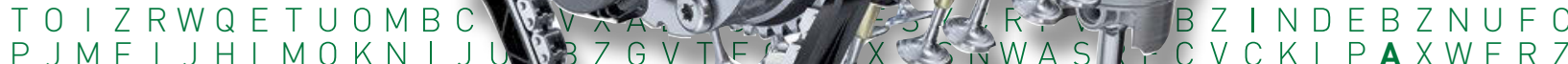

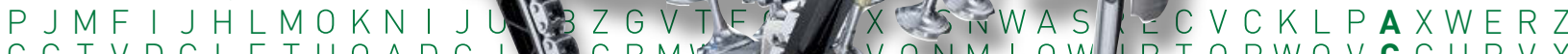

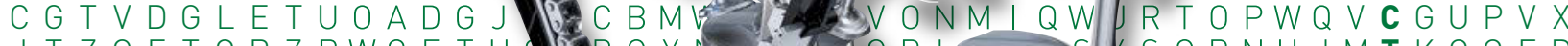

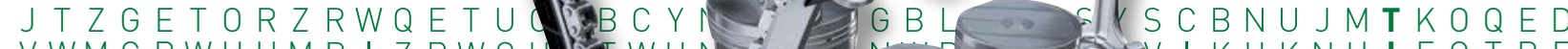
VWMCRWUUMPIZRWOU BWH

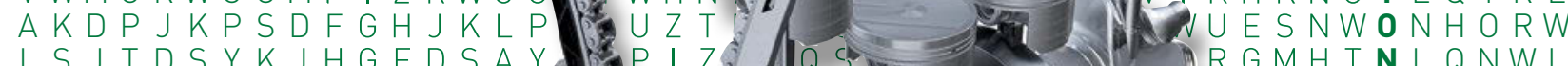

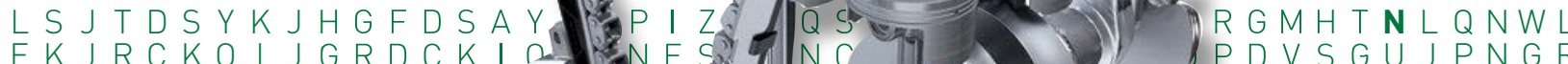

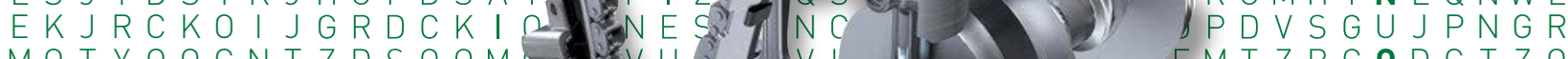
MOTYQOGNTZDSQOMGUUVU EVI VMTZBCODGTZQ TNUEINRLUJGD|NGRE DCOOVCESOPMNVCSEY IIJ J KUVGSAYBGDSNF J Y I ZQYAHINCWQYJAOEZ I W WHBQFGACITFMOSGK

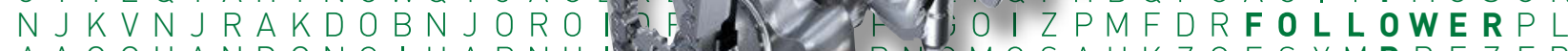

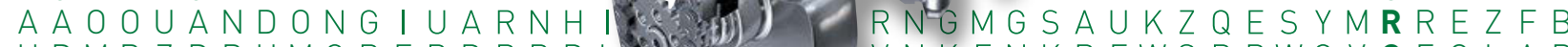
UDMBZDBHMGREBDPBDLU2) VNKFNKREWSPPWQVCEGLAP

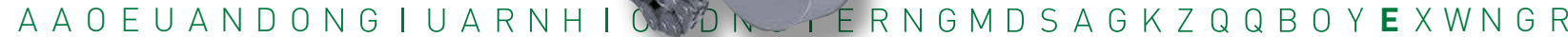
$M O T M Q O G N T Z D S Q O M G D N V U S G R V L G R V K G E C L Z E M N K J S S T O M F B$ UDMTBDAHMGR I B D B D L R B F B A F V K F N K R W S P O Y Q G M F E D $F E \mid D R E Q R$ I UZTREWQLKJHGFDSAMMBVCXYMLMONKOSLWIKAY CIMNSTRECLPQACEZRWDXAYHBMWRZIRFVEGBZACITPMOSF C $P J M N I J H L M O K N$ I JUHBZGVTFCRDXESNWASRECVOCYQDMFERZ C GTJDGLETUOADGJLYCBMWRZIPSFHKTVNZLMONIJBHUZGVX J T Z UETOIZRWQETUOMBCYNVXADGJLKHESYSCBDVSGWJPNED 


\title{
Hidden Potential \\ between the Crankshaft and Valves
}

\section{From the optimization of components to the optimum valve train}

\author{
Dirk Sass
}

Z $v_{1}$

$G Q M H\llcorner$

$|M Q S W|\llcorner\cdots$

E CMBCHSEHヒレ

V V CBSTPOIODCVトᄃ

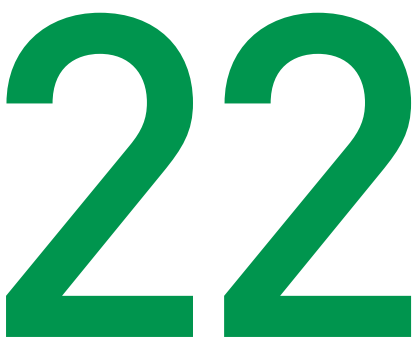

$L M V T Q U J X R E L K J H G F D S A N \mid$

$X \vee M R T X A G Y W P H C E Q A Y W S X E E C K$,

$\vee T \vee N H O U B I J B Z G V T F C R D X E S N W A S K L$

D B T F L U J A D G Y C BMWRZ I P S F H K T V N Z L MU,

C S B P OR UTETMBCYNVXADG JLKHES Y S C B M B

HKSKUPOWRWZTWHNEDKUNWP ONCA LV I K Z TWH IN

I $D X K L P F L K J K O|\cup Z T R E W Q Y X C \vee B N M| Q W U O \mid U Z T R\llcorner$

$Z \cup X A Y H A S G S V N P|Z R W Q S C G Z N J| M N S T R V N P \mid Z R W Q$ _

$U C U K O G \mid K C K P M N E S W L N C X W Z Y K F E D$ I OPPMNESWLNCX

$A T C Z G Z M Q G O D N \vee \cup S G R \vee L G R \vee K G E C E Z E M D N V \cup S G R \vee L G h$ LOTSLOKZ I NEXOMNYAZTEWNFX JLRNIFEXOMNYAZTEW

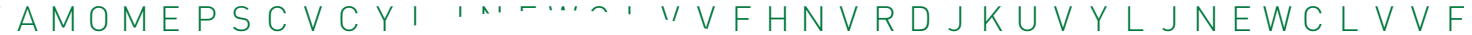
$M N M U A N J Y \cap \cdots+S Q F H B Q F G O B R E L N F X T J C$ I ENSRDO _, IV UnL. I ZPMFDROIDFNGKLDFN,

SAEPNN

I E A T B

$U$ C E P P

$S A C Z$

$G \vee A$

$L M V$

$X \vee \wedge$

$\checkmark T$

$\mathrm{D} B$

C S
$D D L R B E F B A V N K$

. UAH | OGDNO | ERNGM

$O Q O D N V U S G R \vee L G R V K G$

PDBDDLRBEFBAFVNKFN r

, OTRELKJHGFDSAMMBVCX $X A Z Y W P H C E Q A Y W S X E E C R F I$ $O U B \mid J B Z G V T F C R D X E S N W A S$ U JRDGYCBMWRZ I PSFHKTVN $R U T E T M B C Y N V X A D G J L K H E S$ P OWRWZTWHNEDKUNWPONCA $F L K J K O \mid U Z T R E W Q Y X C \vee B N M$ HASESVNPIZRWQSCGZNJIM G I KCKPMNESWLNCXWZYKFF I A S U S V N P I ZRWQSCGZN J I I KCKPMNESWLNCXWZYKF ' OX ODNVUSGRVLGRVKG

1 I NEXOMNYAZTEWN F

C Y L J NEWC LVVFH. $\cap N \vee \cup S G R V L G F$ $\checkmark A \cup K Z Q H|O G D N O| E R N L$

PEWSPDLRBEFBAF VNK

$L K Z Q H|O G D N O| E R N G N$ Z EMDNVUSGR V L GR VK NSPDLRBEFBAFVNKF $M O L K J H G F D S A M M B V$ B ZPHCEQA YWSXEEC $\simeq \vee B Z G V T F C R D X E S N$ 10 Y C B MWR Z I P S F H K BMBCYNVXADGJLK KZTWHNEDKUNWPr 


\section{Introduction}

The design of timing drives in modern internal combustion engines is affected by a large number of parameters, which influence each other. Engine development usually starts from the top down, i.e. with the control of the charge cycle. This approach carries the risk that target conflicts are caused by systems that are taken into consideration at a later date, for example, if adjustment of the timing drive to suit the special design features of the crankshaft results in negative effects for the camshaft phasing system.

Experience shows that the development process currently used cannot realize all the available optimization potential. The challenge is to define all subsystems in detail at the very beginning of development so that the optimum is achieved at system level. This type of demanding development work can only be managed if all departments involved both from the automobile manufacturer and the supplier - collaborate even more intensively. The organization must allow component development experts to use the available inhouse systems expertise at any time.

\section{The entire system}

\section{Definition}

The entire timing drive system includes the camshaft drive itself with a chain or belt, the camshaft phasing unit and the different designs of valve actuation (Figure 1). This may also include a spur gear - if only one of the two overhead camshafts are directly driven - as well as the connection to the crankshaft.

\section{Higher-level development targets}

The target of designing an optimum valve train follows the normal premises of engine development: The priority is to safeguard

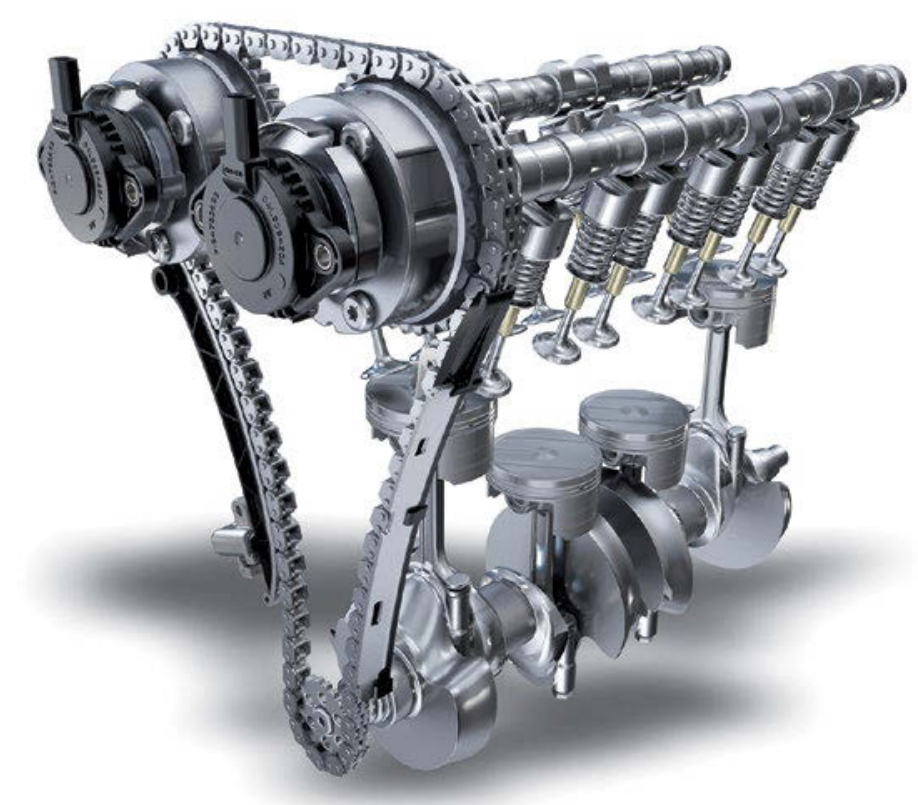

Figure 1 The entire timing drive system: Camshaft drive with a chain as in this photo or with a belt, camshaft phasing unit and different designs of valve actuation 
the function of individual systems throughout the operating life. An additional focus of development is placed on minimizing friction in the entire system. Almost as much importance is now attached to this task as achieving the functional targets. Efforts to minimize noise emissions and, in particular, the moving mass have also become established development tasks. Today's preferred designs are derived from these requirements. The procedures used for developing valve train systems for many years have led to a great deal of expertise in this area. This means it is possible to draw up a design proposal for the valve train during the concept phase of the engine. And this is precisely where the dilemma starts: What might be the optimum valve train design can have grave disadvantages for the following systems and vice versa. The typical development process of a valve train describes this challenge.

\section{Initial situation in development}

The main approach in engine development is to define the charge cycle processes. This ensures that the most important requirements in the requirements specification such as power, torque and exhaust gas values are met. The first individual system to be considered is therefore the valve train. In this development stage, it is important to select the optimum concept for the relevant application from numerous possible variants. During the second stage, a decision is made on whether and to what extent phase position adjustment of the camshafts is required. It is worth mentioning that responsibility is frequently transferred to another department during this phase. Different employees design the timing drive during the third stage and integrate it into the engine while taking the first of the above mentioned restrictions into consideration. Work is usually carried out on a phased basis. With this approach, each individual development department must adhere strictly to the requirements, regardless of the knowledge that the requirements for the adjacent systems can force them to use a design for their own component, which falls short of the optimum in certain circumstances. Frequently, only marginal adjustments of the requirements for adjacent functions would be sufficient to open up new options for the system under development.

The assessment of this process shows both sides of the coin: On the one hand, extensive expertise is created up to the subsystem and component levels. On the other hand, it enables the realization of a global optimum using, in principle, unnecessary iterations. This dilemma can be solved if the automobile manufacturers involve their suppliers in development at the beginning of the concept phase in order to combine the expertise at component and system level of all those involved. A comprehensive consultation is most effective during this early phase. Some examples based on practical experience illustrate the potential for improvement.

\section{Approaches for optimizing friction}

With mechanical or hydraulic tappets, roller tappets, roller followers or finger followers, development engineers have a wide variety of reliable technologies that have been tested worldwide. Well designed 


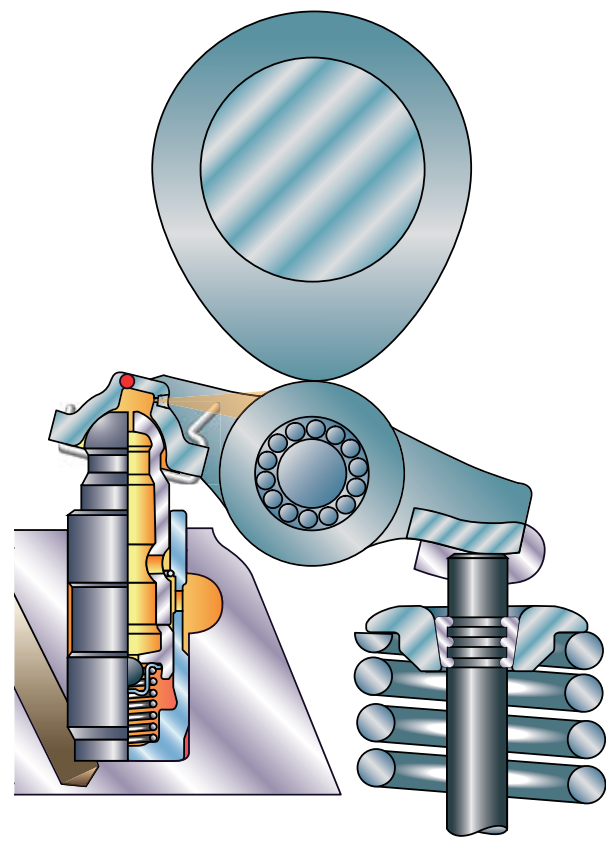

Figure 2 Example of a "pulled" follower

roller-type finger follower valve trains in combination with hydraulic pivot elements usually have significant advantages with regard to their friction behavior compared to other concepts. This conclusion was reached after carrying out extensive tests on externally-driven cylinder heads. The arrangement of the camshaft in the cylinder head in relation to the space between the hydraulic pivot element and valve stem end can require a mounting position of the finger followers, which Schaeffler describes as a "pulled" follower arrangement (Figure 2).

Further tests of the finger follower valve train have shown that the "pulled" follower has advantages over the "pushed" follower arrangement. This is because skewing of the "pushed" follower occurs under load due to its design (Figure 3). The "pulled" follower prevents this because it is self-aligning.
This is because the load is applied differently to the the follower by the cam. In a "pushed" valve train, the cams can cause misalignment in an axial direction at one end of the finger follower at low to medium speeds. At the other end, the follower is located in position on the pivot element by a spherical piston head, which acts as a guide. "Pushing" in a lateral direction is prevented by the geometry at the pivot element so that the resultant force acting on the follower cannot generate any further movement. At the other end, the lateral guides of the finger follower are in contact with the valve stem so that an equilibrium of forces exists between the valve and the cam. The forces acting through all the followers on the entire shaft are totalized because the finger followers usually have a preferred direction. The simulation of this arrangement shows that the entire camshaft is ultimately pressed into its axial bearing support. Corresponding tests clearly confirm the theoretically derived motion for all the tested parameter variations.

The increased force in the direction of the camshaft axis causes a higher drag torque of the cylinder head - which is greater if conventional plain bearings are used. Tests have confirmed the conclusion that rolling bearings are advantageous here. This effect is reduced with increasing speeds because the time available for the cam lift is not sufficient to cause a significant increase in the axial force.

In the case of the pulled valve train design, the movement of the cam "pulls" the finger follower directly away from its fixed point - the spherical piston head on the pivot element. This process is comparable with pulling a conventional suitcase on two rollers: The handle corresponds to the spherical piston head as the location, and the force is also applied here via the rollers, only on the floor instead of via a 


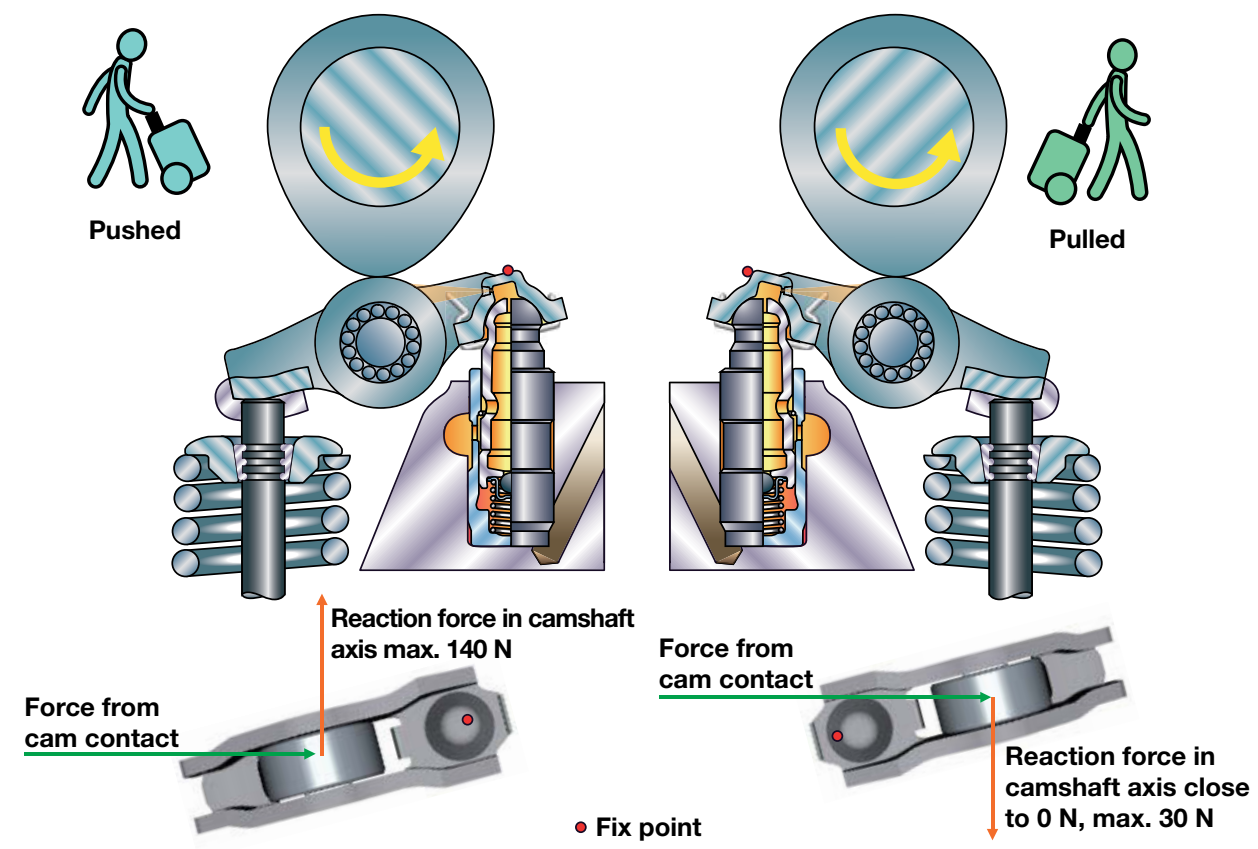

Figure 3 Comparison of forces acting on a "pulled" and a "pushed" follower

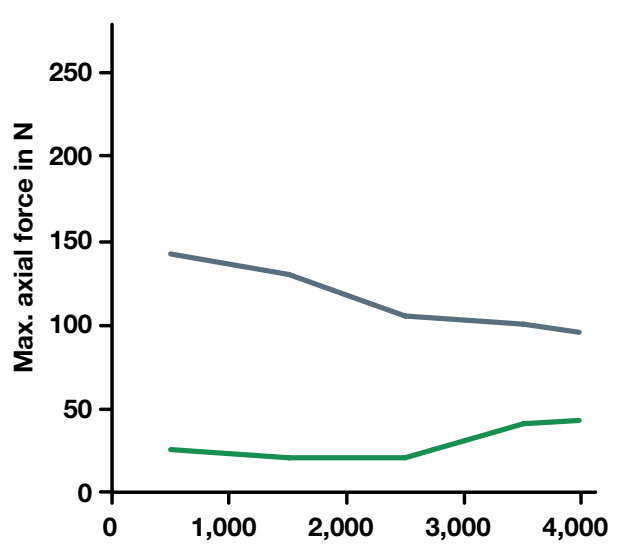

Engine speed in rpm

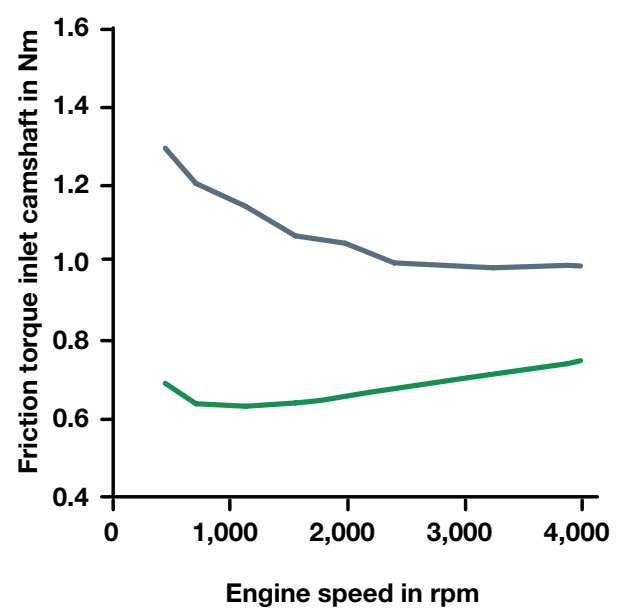

$$
\begin{aligned}
& \text { - pushed } \\
& \text { - pulled }
\end{aligned}
$$

Figure 4 Friction of a "pushed" follower compared with a "pulled" follower in relation to the speed 
cam. The resulting "pulling" force aligns the case in a straight line. However, if the case is pushed, it will veer to the side after a short distance. This pushed arrangement corresponds with the "pushed" follower.

The force values recorded in comparison measurements correlate consistently with the friction measurements and verify the theory that with this combination no relevant transverse forces act on the camshaft. In a comparison of both directions of

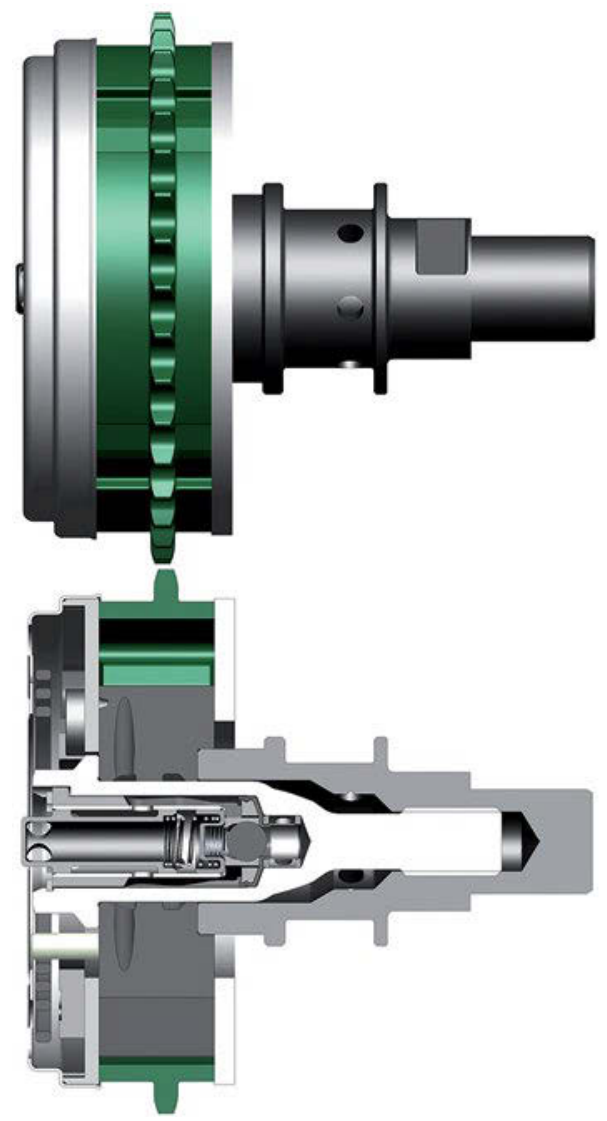

Figure 5 A positive example: The camshaft phasing unit is narrow, the sprocket is located on the camshaft camshaft rotation, the "pulled" follower concept has approximately $40 \%$ less friction at low speeds (Figure 4). This direction of camshaft rotation has around $30 \%$ less friction at a speed of 4,000 rpm.

The camshafts must be suitably positioned in order to realize this type of finger follower arrangement. The decisive reference point is the position of the finger follower roller. The boundary conditions for the timing drive and particularly for the phasing unit change significantly depending on this position.

The distance between the camshafts in combination with the maximum section height of the engine - this is defined from the requirements for the protection of pedestrians - are the most important specifications for subsequent designs.

\section{Challenges during the optimization of the entire system}

\section{Camshaft phasing units}

A suitable camshaft phasing system is selected according to the required adjustment speed and adjustment force as well as the adjustment angle, which must be covered. The oil pressure is also a relevant input variable because hydraulic systems are normally used. The required performance data determine the effective hydraulic surfaces and therefore the minimum size of the system. However, the available mounting space is usually limited. If the ideal position of the camshafts in relation to the adjacent construction is not possible it will have the following implications: The maximum possible outside diameter for the phasing unit is automati- 
cally reduced if there is a smaller distance between the camshafts. But if the camshafts have to be positioned further apart, they may be too close to the lateral limits of the cylinder head or valve cover. In this case, the only solution is to extend the design envelope in a longitudinal direction to ensure the phasing unit has the required hydraulic power. The first conflict of objectives occurs if this solution is not possible. However, not all the questions are answered even if a phasing unit with a longer design is possible (Figures 5 and 6): The latter must be screw mounted, i.e. the cover and sprocket are clamped together by a number of screws, which pass through the phasing unit. The forces required are relatively high and the design of the screw connection is very complex and critical. In addition, the sprocket is no longer directly located on the shaft. In contrast to a sprocket fitted directly on the shaft, the screw connection leads to tolerances, which affect the radial runout of the system. This imbalance causes additional excitations, which can impair the adjustment function, or have further disruptive effects on the smooth running of the timing drive.

The outside diameter of a phasing unit with a specified length is not only defined by the power requirements of the hydraulic system but also by the specified ratio of 1:2 between the teeth on the crankshaft and camshaft. This requires a fixed number of teeth - usually an even number - on the camshaft. Not all possible combinations can be realized in practice: If the "correct" combination in relation to the number of teeth required on the camshaft results in an outside diameter, which does not allow the specified distance between the camshafts, it cannot be implemented as in the converse case. The system is then too small and cannot transmit the required power due to physical reasons.
This can ultimately mean that the targets must be changed or a completely different solution must be developed. One alternative is an arrangement where only one camshaft is directly driven by the timing drive. This means the problem regarding the restricted space between the camshafts is rectified and the outside diameter is only limited by the section height of the engine in the vehicle. This is generally the normal approach for timing drives although this measure

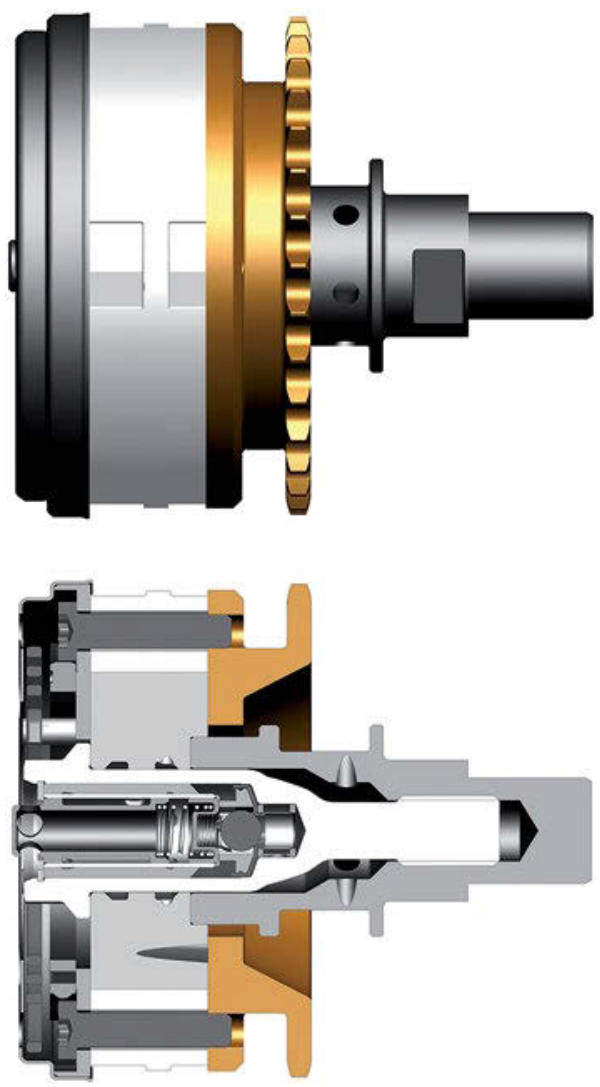

Figure 6 A negative example: The cover and sprocket of the phasing unit are clamped together by means of screws. Any tolerances can affect the radial runout. 
does have an impact if the engine is considered as a whole.

Firstly, a drive must be provided for the second camshaft - either a second chain or belt drive or a spur gear stage. This always creates additional space requirements in the longitudinal direction of the engine. In certain circumstances, the camshafts must also be extended. The design of the cylinder head and valve cover is significantly more complex on this side. Even an oil supply must be integrated if a hydraulic tensioner is required for an additional chain drive. Firstly, this means an additional consumer must be taken into consideration in the oil system. Secondly, it results in an increased outlay when designing the oil ducts. These changes inevitably result in a heavier and more expensive engine. Additional process steps are also required in volume production assembly. Because more highly-dynamic components are used, the system is also more susceptible to vibration and noise generation, which can sometimes only be managed by using complex solutions; this applies especially to spur gear stages.

Last but not least, these components also generate friction in addition to noise, weight and costs. The resultant friction losses under unfavorable conditions are larger than those, which the change to a "pulled" valve train eliminated. In the worst case, the net result is worse than a concept where compromises have been made in the design of the valve train if it is equipped with an optimum camshaft phasing system.

\section{Track position of the chain or belt drive}

In addition to the design analysis described above, the position of the chain or belt track relative to the first camshaft bearing has a significant influence on the phasing unit concept. If there are many unfavorable requirements resulting from the design and arrangement of the adjacent components, this can lead to solutions as shown in Figure 7.

There are noticeable restrictions for the required phasing unit concept. The stator implemented here may be regarded as a sophisticated design but its manufacture is very expensive. Further costs are incurred during manufacturing because additional quality assurance measures are required. Clever positioning of the track for the chain or belt drive would allow a phasing unit design, which not

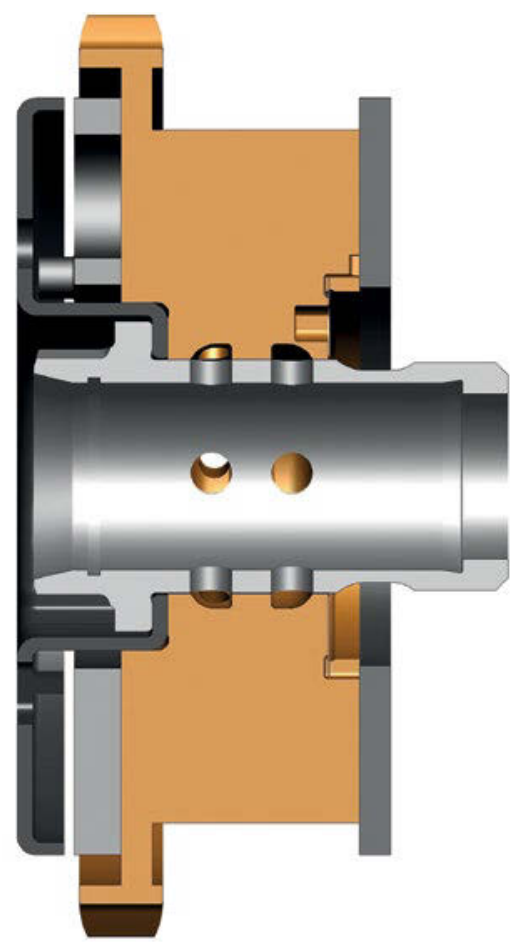

Figure 7 A negative example: The phasing unit gear is connected via a narrow web. Manufacture of the stator is expensive. 


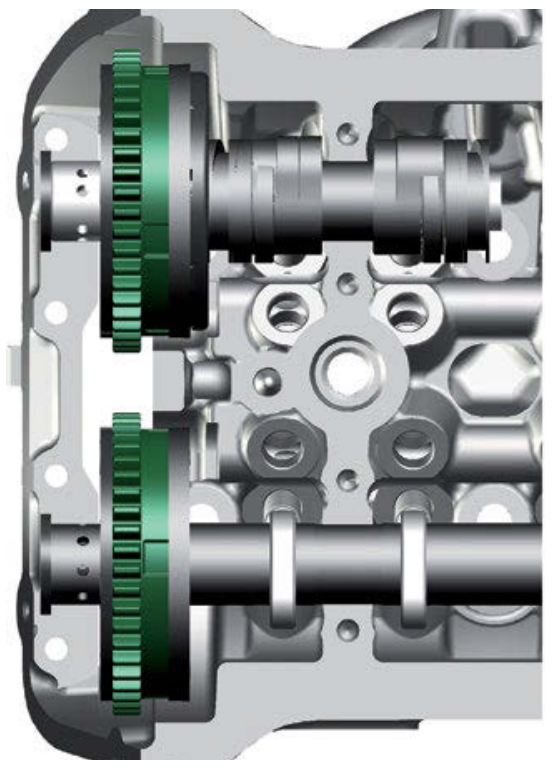

Figure 8 A positive example: The chain runs centrally in the chain tunnel only operates more efficiently but also has a positive influence on the timing drive due to its reduced mass (Figure 8). Lightweight components usually cannot fully compensate for the increased weight of a design because they soon reach their limits with regard to component strength.

\section{Selection of the chain or belt drive}

The decision about whether the requirements are better met by using a chain or a belt timing drive must be clarified initially depending on the complexity and number of shafts to be driven. Chain drives and dry toothed belt drives have the longest history on the market and have reached a corresponding level of sophistication (Figure 9). In contrast, the wet belt or $\mathrm{BiO}$ (belt in oil) is still a new product. If correctly designed, all three types of drives are com-
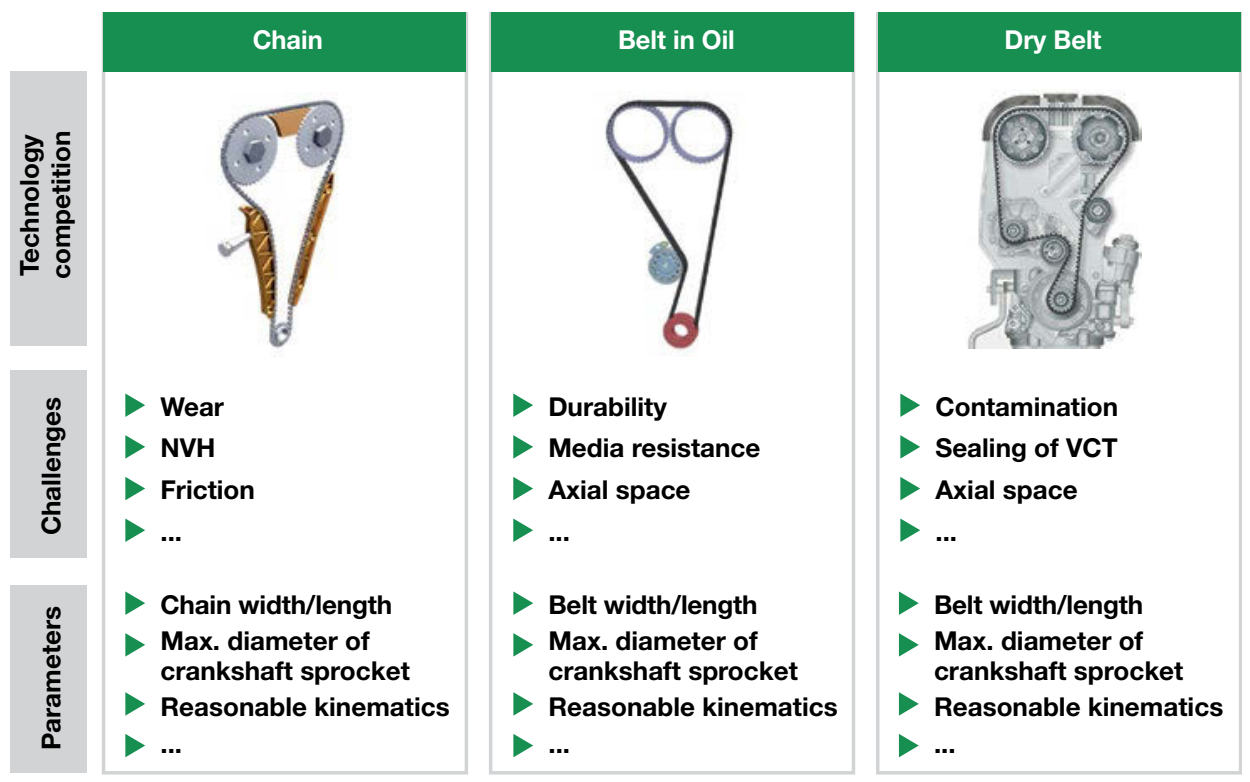

Figure 9 Whether it is a chain, belt in oil or dry belt: The specific requirements determine the selection of the chain or belt drive 
parable with regard to their operating life. Irrespective of the type of chain or belt drive used, it is important to start the detailed design at an early stage in order to precisely work out all the potentials and risks. Even if it has favorable prerequisites, an effective, low-friction system can still fail to meet the targets with regard to important parameters. In some cases, moving the location of the camshaft by just a few tenths of a millimeter is sufficient to turn a good system into an unsatisfactory system.

\section{Belt}

If a decision is made to use a dry toothed belt, the engine and camshaft phasing units must be sealed against the ingress of oil from the engine's oil circuit. This negative effect is compensated by the advantage that a high measure of flexibility is maintained during the implementation of the design. A belt in oil eliminates this disadvantage. This can result in a slight advantage with regard to noise emissions due to the integration of the belt into the engine, although this depends on the application. The belt in oil allows the same degree of design freedom as the dry belt. In comparison to a chain, both designs of belt have the advantage that timing belts with an odd number of teeth can be manufactured. This means it is easier to make adjustments to the entire arrangement. In contrast, smaller sprocket diameters are possible with chains without having a detrimental effect on the operating life.

\section{Chain}

As in the case of a belt, the first step is usually to determine the required number of sprocket teeth on the shafts. Ideally, the number should be as large as possible in order to minimize the polygon effect. At the same time, a check is made to ensure that the number of chain links re- quired is not a common multiple of the number of teeth on the crankshaft sprocket. This results in improved noise and wear behavior. The length of chain required is determined from the number of teeth and the distance between the shafts. Chain drives can only be manufactured in variants with an even number of chain links. This has a significant influence on the chain line. It is worthwhile investing sufficient time in consideration of the possible variants with regard to chain pitches, the possible number of teeth and design of the chain line. An ideally designed chain line usually ensures quiet and dynamically correct running of the entire system in the fired engine. It also forms the basis for a low-friction system.

\section{Interdependence with adjacent components}

Individual boundary conditions, for example design envelope requirements, are occasionally so restrictive that they lead to functional impairments. This can mean that chain guides with pronounced curves must be inserted in the driving side of the chain drive. These inevitably increase the friction due to the higher normal forces. This also applies for a belt if it requires a pulley on the driving side.

The slack side is assessed differently. Excitations on the system resulting from dynamic chain loads are damped by the chain tensioner via the tensioning rail arranged on the slack side of the chain drive. The form of the rail affects the way and intensity, with which these impulses are transmitted. However, the first impression does not always correspond with the actual result: A clever design even one with small radii - allows lower mean chain forces to be achieved than in chain drives designed to reduce the normal force acting on the sliding layers by means of an exaggerated "straight" guide. 


\section{Summary}

The current structures in development departments correspond to the technical content of their systems. This is why it is difficult to consider all the systematic effects of valve control components. Experience at Schaeffler shows that optimization at component level does not often lead to the best possible result with regard to the entire system. In the worse case, for example, the net result of an optimized valve actuation system is worse than a concept which allows compromises in the design of the valve train if it is equipped with an optimum camshaft phasing system. This situation can ultimately mean that the targets must be changed or a completely different solution must be developed. Current projects confirm that the automobile manufacturers come to the same conclusion in their analysis of the development process. Their are different approaches for implementing a more efficient development process. Schaeffler achieves this by bundling all development and application engineering departments in one organization. It is also helpful if all the components of interactive systems are jointly developed at all locations. This simplifies matching the components to one another. It is highly recommended that system suppliers are involved in the new and further development of valve trains at the earliest possible stage. This allows the opening up of potential that was previously unused and rapidly leads to success.

Open Access. This chapter is distributed under the terms of the Creative Commons Attribution Noncommercial License, which permits any noncommercial use, distribution, and reproduction in any medium, provided the original author(s) and source are credited. 